\title{
GOVERNO DAS POPULAÇÕES, CIRCULAÇÃO DE PESSOAS E PRODUÇÃO DE ALTERIDADES: ELEMENTOS PARA A DESCOLONIZAÇÃO DO DEBATE
}

\author{
GOVERNMENT OF THE POPULATIONS, CIRCULATION \\ OF PEOPLE, PRODUCTION OF ALTERITIES: \\ ELEMENTS FOR DECOLONIZATION OF DEBATE
}

\begin{abstract}
Alex Martins Moraes*
RESUMO: Neste artigo tomo os referentes epistemológicos originados no paradigma descolonial para conduzir um debate conceitual passível de ser apropriado ao horizonte empírico da investigação etnográfica. Começo a discussão refletindo sobre as noções de governo e população tal como Foucault sugere abordá-las em seus cursos de finais da década de setenta. Em seguida reviso criticamente um estudo específico sobre controle estatal da circulação internacional de pessoas - trata-se do emblemático livro de John Torpey, $A$ Invenção do Passaporte - com o duplo objetivo de contrastar matrizes conceituais e ampliar categorias analíticas. Por fim, avalio de que forma o debate descolonial sobre construção de alteridades pode ser inserido na análise empírica dos movimentos migratórios, especialmente na região do Cone Sul. Neste ponto retomo brevemente alguns aspectos de meu trabalho etnográfico com trabalhadores indocumentados em zonas fronteiriças do Mercosul para demonstrar o potencial evocativo das ideias apresentadas.
\end{abstract}

Palavras chave: migrações, alteridade, governamentalidade, descolonidadade, etnografia.

\footnotetext{
* Mestrando do Programa de Pós-Graduação em Antropologia Social da Universidade Federal do Rio Grande do Sul - UFRGS, Porto Alegre, Brasil, e-mail: alexmartinsmoraes@gmail.com
} 
ABSTRACT: In this article I want to deepen a specific epistemological debate (the debate on coloniality of savoir-pouvoir and its necessary conexion with the critical theoretical traditions originated in marxism and post-structuralism), trying to adapt the concepts discussed at the empirical horizon of ethnographic research. I start the discussion reflecting on the notions of government and pupulation as Foucault suggests addressing them in their late-seventies courses at the Collège de France. Then I make a critical review of an important study on state control of people's movement (the book "The Invention of Passport" by John Torpey) with the dual purpose of comparing theoretical frameworks and expand analytical categories, trying to relate them to the broader perspective adopted in this work. Finally, I evaluate how decolonial discussion on construction of otherness can be inserted in the empirical analysis of migration, especially in the Southern Cone. At this point, I present brief ethnographic examples, not to make conclusive comments but to demonstrate how evocative can be the ideas that have been presented.

Key-words: migration, alterity, governmentality, decoloniality, ethnography.

\section{INTRODUÇÃO}

Neste artigo desenvolvo alguns aspectos conceituais para o estudo da inter-relação entre governo de populações, movimentos migratórios e fabricação de alteridades. Sem a pretensão de encaminhar um levantamento exaustivo da literatura relativa aos três temas, minha proposta é abordá-los tendo em vista uma das perspectivas teóricas que mais contribuiu para a refundação das ciências sociais no continente latino-americano. Refiro-me às discussões promovidas pelo grupo modernidade/colonialidade, as quais têm proporcionado um espaço de interlocução que envolve diversos investigadores, professores e estudantes vinculados a instituições acadêmicas e não acadêmicas espalhadas por toda a América. Eduardo Restrepo (2010) recorre ao termo "coletividade de argumentação modernida- 
de/colonialidade" para ressaltar que o grupo em questão vêm atualizando uma agenda sistemática de eventos, seminários, debates via internet e escrita de textos individuais que incluem referências mútuas, ao mesmo tempo que expressam ênfases teóricas e programas de pesquisa singulares.

A emergência do grupo modernidade/colonialidade remonta à segunda metade da década de noventa, ainda que os intelectuais envolvidos nesse projeto reflexivo possuíssem, já, uma longa trajetória criativa em instituições de ensino situadas tanto na América Latina como nos Estados Unidos. Não é meu objetivo apresentar um panorama geral do "estado da arte" da crítica descolonial, posto que esta tarefa demandaria um exercício textual específico, como aqueles que já foram realizados, em diferentes momentos, por Arturo Escobar (2003), Eduardo Restrepo e Axel Rojas (2010). No entanto, para fins de contextualização, é possível dizer que o debate descolonial foi fortemente inspirado pelos trabalhos seminais de Aníbal Quijano (2007), Enrique Dussel (1992, 1999) e Walter Mignolo (1995, 2000), e ancorou-se em algumas operações analíticas que o descolam das teorias da modernidade dominantes no contexto acadêmico ocidental. Escobar (2003) sintetiza essas operações da seguinte maneira:

1) uma ênfase em localizar as origens da modernidade na Conquista da América e no controle do Atlântico depois de 1492 e não em referência aos marcos que são mais comumente aceitos, como a Ilustração ou o final do século XVIII; 2) uma atenção persistente no colonialismo e no desenvolvimento do sistema mundial capitalista como constitutivos da modernidade; isto inclui uma determinação de não negligenciar a economia e suas concomitantes formas de exploração; 3) em consequência do anterior, adoção de uma perspectiva planetária na explicação da modernidade, em vez de concebê-la como fenômeno intra-europeu; 4) a identificação da dominação de outros fora do centro europeu como uma necessária dimensão da modernidade, com a concomitante subalternização do conhecimento e das culturas desses outros grupos; 5) uma concepção do eurocentrismo como a forma de conhecimento [por excelência] da 
modernidade/colonialidad - uma representação hegemônica e um modo de conhecimento que advoga por sua própria universalidade [...] (Escobar, 2003, p.60)․

Colonialidade do poder é a categoria central para o grupo "modernidade/colonialidade". Com ela, pretende-se evidenciar que a derrubada dos governos coloniais europeus em África, Ásia e América não fez ruir as estruturas de longa duração fundadas nos século XVI e XVII, resumindo-se, apenas, em uma descolonização jurídico-política das periferias que não abalou sua dominação epistêmica e tampouco desestabilizou as formas de exercício do poder e do controle social inauguradas durante a fase especificamente colonial do sistema-mundo ${ }^{2}$. Nesta perspectiva, o capitalismo segue atualizando as exclusões provocadas pelas hierarquias epistêmicas, espirituais, raciais/étnicas e de gênero/sexualidade desdobradas pela modernidade eurocentrada (Castro-Gómez; Grosfoguel, 2007, p. 14). Referidas hierarquias atualizam-se através de arranjos específicos entre processos culturais e econômicos ordenados em escalas diversas, onde atuam múltiplas formas de dominação e resistência sem que nenhuma delas tenha incidência determinativa ou causal sobre a outra, ainda que mantenham, entre si, certa interdependência complexa. Trata-se, portanto, de uma heterarquia dinamizada por articulações ortogonais entre princípios ordenadores diversificados.

A dimensão política da crítica descolonial reside em seu esforço por indagar constantemente sobre as origens espaciais e temporais da modernidade, desatando, assim, o potencial radical de se construir discursos alternativos de poder informados pela práxis cotidiana dos grupos subalternos (Escobar, 2003). Neste sentido,

\footnotetext{
${ }^{1}$ Todas as citações retiradas de referências bibliográficas em castelhano foram traduzidas ao português pelo autor

${ }^{2}$ Em sua revisão dos debates descoloniais desenvolvidos ao longo da primeira década do século XXI, Eduardo Restrepo e Axel Rojas sugerem a seguinte definição de "colonialidade": A colonialidade é um fenômeno histórico muito mais complexo [do que o colonialismo] que se estende até o presente e se refere a um padrão de poder que opera através da naturalização de hierarquias territoriais, raciais, culturais e epistêmicas [...] esse padrão de poder não apenas garante a exploração, pelo capital, de alguns seres humanos por outros a escala mundial, mas também a subalternização e obliteração dos conhecimentos, experiências e formas de vida daqueles que são dominados e explorados dessa maneira (Restrepo; Rojas, 2010, p.15)
} 
questionar-se sobre a colonialidade implícita nos fenômenos sócioculturais e econômicos associados tradicionalmente à modernidade (estados-nacionais, códigos jurídicos, razão instrumental, capitalismo, etc.) significa aceitar que sua lógica e raison d'etre respondem a conflitos específicos que nunca estiveram circunscritos ao espaço europeu, senão que emergiram como resultado de interações assimétricas desencadeadas nos domínios coloniais do sistema-mundo. Falar em "modernidade-colonialidade" implica reconhecer, portanto, que o primeiro elemento do binômio não pode ser entendido sem referência aos processos históricos evocados pelo segundo termo.

Ao trabalhar com um marco analítico que poderíamos classificar como eurocentrado, alguns teóricos estão perdendo de vista a operatória da colonialidade do poder, o que lhes impede de analisar satisfatoriamente o sentido e as origens de diversos processos sociais cuja emergência eles tendem a associar à conjunturas exclusivamente intra-europeias. Começo a discussão do presente artigo refletindo sobre as noções de governo e população, tal como Michel Foucault sugere abordá-las em seu curso intitulado Segurança, Território, População, ministrado no Collège de France em finais da década de setenta. Este procedimento me permite selecionar algumas categorias que serão recontextualizadas em referência ao horizonte colonial inerente ao projeto da modernidade. Orientado por essa revisão conceitual, desenvolvo a leitura crítica de certos argumentos levantados pelo sociólogo estadunidense John Torpey em seu emblemático livro intitulado A Invenção do Passaporte (2003). Meu estudo da obra de Torpey responde ao objetivo de alcançar, mediante contraste de matrizes conceituais e recortes metodológicos, uma ampliação das categorias analíticas disponíveis ao estudo antropológico das dinâmicas de deslocamento internacional e governo das populações, entendidas, ambas, como fenômenos privilegiados para problematizar o funcionamento do poder na modernidade. No terceiro tópico, avalio de que forma o debate descolonial sobre produção e hierarquização das alteridades pode contribuir à análise dos movimentos migratórios em geral e das migrações no Cone Sul em particular. Aqui também retomo alguns contextos da investigação empírica, não para tecer comentários conclusivos ou 
para ilustrar a validade dos pressupostos teóricos assumidos, e sim para demonstrar como as reflexões sobre colonialidade e governo das populações podem ensejar uma apresentação complexa da operatória do poder social nos cenários contemporâneos da investigação qualitativa. Por fim, sugiro que uma reconceitualização da categoria "lugar" pode garantir à etnografia um ponto privilegiado para a observação do impacto concreto que as dinâmicas sistêmicas referidas ao longo do texto exercem sobre a vida cotidiana e a práxis social das pessoas de carne e osso.

\section{GOVERNO DAS POPULAÇÕES}

Na acepção de Foucault, a população emerge como um sujeito absolutamente novo em determinados discursos de poder originados na Europa do século XVIII. Em seu curso Segurança, Território, População (1977-1978), oferecido no Collège de France, o autor procura reconstruir os elementos que compõem este novo nível de realidade a partir do qual os fenômenos da vida do ser humano como espécie virão a se converter, progressivamente, em uma questão de governo e de política(s). Foucault nos sugere que a emergência do dispositivo de população marca o início de uma era na qual as preocupações do poder passam pela necessidade de regular a forma como vivem os sujeitos, sob a justificativa resguardá-los da alienação e torná-los aptos para o bom funcionamento da sociedade, da economia e do mercado ${ }^{3}$. Esta arte de governar que se inaugura no século XVIII, se aprofunda no século XIX e se estende - englobando, com o passar do tempo, novos saberes e racionalidade políticas - até o século XXI, foi chamada de governamentalidade.

Foucault oferece-nos diferentes e complementares definições para a noção de população. Numa primeira acepção, ela pode ser entendida como o nível de realidade sobre o qual atuará o "dispositivo

\footnotetext{
${ }^{3}$ Não devemos compreender a sucessão de matrizes de exercício do poder como um processo evolutivo, no qual uma arte de governar sucederia a outra cronologicamente. Os diferentes dispositivos de poder aparecidos no decurso da história articulam-se ortogonalmente - diria Foucault em Em defesa da sociedade (1999) - sem que, necessariamente, um dê lugar ao outro de forma definitiva. 118| Século XXI, Revista de Ciências Sociais, v.2, nº 2, p.113-148, jul./dez. 2012 
de segurança"4 no âmbito da moderna arte de governar. Este nível de realidade inclui a multiplicidade de indivíduos que estão e só existem profunda, essencial, biologicamente ligados à materialidade dentro da qual existem (Foucault, 2006, p. 42). Tal como visualizado pela nova estratégia de poder, este sujeito-objeto "população" estende-se, conceitualmente, desde o substrato biológico expresso na espécie até a superfície de apoio apresentada pelo público ${ }^{5}$ (Foucault, 2006, p. 102). O espectro do vasto universo fenomênico que o recorte da população permitiu visibilizar e integrar ao horizonte estratégico do governo será explorado por diferentes saberes, será acessado por variados mecanismos de poder; será, enfim, um espaço válido de atuação e, mais do que isso, uma dimensão sobre a qual se deverá atuar no intuito de garantir a governação estatal.

O que singulariza o governo das populações frente às outras formas de exercício do poder que Foucault havia estudado em trabalhos anteriores? E lícito dizer que, enquanto o poder soberano e o poder disciplinar enfocavam o indivíduo e nele atuavam mediante coerção ou disciplinamento, a governamentalidade enfoca a população e busca manejá-la operando as variáveis "naturais" do meio, sendo este entendido como um espaço de circulação de causas e efeitos associados a fenômenos físicos, políticos e de índole individual:

(...) o meio aparece (...) como um campo de intervenção onde, em vez de afetar os indivíduos como um conjunto de sujeitos de direito capazes de ações voluntárias - assim ocorria com a soberania -, em vez de afetá-los como uma multiplicidade de organismos, de corpos suscetíveis de prestações, e de prestações exigidas, como na disciplina, se tratará de afetar, precisamente, uma população. (Foucault, 2006, p. 41)

\footnotetext{
${ }^{4} \mathrm{O}$ dispositivo de segurança faz alusão a um conjunto de dinâmicas (psicológicas, de mercado, de organização da produção, de formação de mercados, etc) que, caso forem resguardadas e estimuladas, serão capazes de garantir a estabilidade, a expansão e o aperfeiçoamento do sistema político e econômico vigente. Este tema será mais bem elaborado mais adiante neste tópico.

5 O "público" nada mais é do que a dimensão opinativa, volitiva da população. É a população com opiniões e anseios, é tudo aquilo que não diz respeito apenas à reprodução biológica dos sujeitos e às variáveis físicas que podem impactar sobre sua existência.
} 
Torna-se importante, então, desenvolver mecanismos de intervenção sobre o meio para acessar vantagens estratégicas no governo da população. Trata-se de gerir as relações dos sujeitos com sua realidade material almejando a optimização das condições de existência de todos. Isto não quer dizer que o indivíduo tenha sido excluído do rol de preocupações associadas a arte de governar. Deuse, na verdade, um deslocamento de objetos de poder. Todas as técnicas existentes para o manejo dos indivíduos - bem como as premissas das quais elas partem (contrato, concepção jurídica da pessoa, biologização do corpo) para garantir sua efetividade - serão postas ao serviço do objetivo de se obter algo no plano da população: $A$ população é pertinente como objetivo e os indivíduos, as séries de individuos, os grupos de indivíduos, a multiplicidade de indivíduos, por sua parte, não serão pertinentes como objetivo (Foucault, 2006, p. 63). Inaugura-se, portanto, um novo nível de exercício do poder.

Foram os fisiocratas de meados do século XVIII que conferiram à noção de população o significado que pôde estabilizá-la como sujeito-objeto da governamentalidade moderna. Antes deles, no entanto, os mercantilistas já haviam erigido a população como elemento de interesse do poder soberano, situando-a na base da riqueza do Estado, onde deveria estar regimentada por todo um aparelho regulamentar que impedirá a emigração, atrairá os imigrantes e favorecerá a natalidade (...) (Foucault, 2006, p. 91). Nas épocas áureas do mercantilismo, a população foi encarada como uma força produtiva cujo conteúdo de utilidade restringia-se à esfera da produção. Após o fracasso sistemático das políticas de regulação da atividade comercial e produtiva defendidas pelos mercantilistas, o argumento fisiocrático começou a ganhar legitimidade entre os governantes dos estados-nação mais poderosos da Europa. Desta maneira, as estratégias econômicas nacionais passaram a enfatizar o incremento da produção agrícola e - o que é importante para desdobrar minha análise - a desregulamentação do sistema produtivo.

Como é sabido, as teorias fisiocráticas chamavam atenção para a existência de uma lei natural que asseguraria o bom funcionamento da economia com a condição de que os governos a deixassem 
vigorar livre de quaisquer amarras "artificiais". Os fisiocratas estenderão a "economia" - que antes descrevia nada mais que a arte de bem governar os ingressos e o patrimônio de uma unidade doméstica, valendo-se dos recursos disponíveis em sua dimensão humana e física - ao nível da nação. A gestão adequada da economia nacional dependerá, então, da sapiência do soberano no manejo da população que, por sua vez, também possui uma "naturalidade" intrínseca e leis que lhe são imanentes. O governo que almeje prosperidade precisará munir-se de algumas ferramentas capazes de mapear as leis que regem o funcionamento da população. Apenas tomando conhecimento destas leis, o governante poderá manipulá-las no horizonte de sua estratégia de poder. Temos, desta forma, que a população reaparece no discurso dos fisiocratas não mais como conjunto de indivíduos submetidos à vontade soberana, mas como um campo fenomênico que possui sua própria "natureza", independente do desejo de quem quer que seja.

Demarcadas as diferenças entre a ideia de população que matiza a governamentalidade moderna desde o século XVIII e aquelas que pautaram o pensamento de Estado em momentos anteriores, atenhamo-nos, agora, à "epistemologia" desenvolvida para governar este novo sujeito-objeto do poder. Em meados do século XVIII, natureza e sociedade já não eram representadas nos termos de uma oposição absoluta. No pensamento fisiocrático, a "natureza" não consiste no reino da desordem e do caos - da incerteza, ao fim e ao cabo - em contraste com a "ordem" que caracteriza o contrato social. Tanto uma coisa quanto a outra originam fenômenos regulados por leis sui generis, acessíveis a determinados saberes e suscetíveis de determinadas formas de apropriação.

Como medir as leis imanentes à "naturalidade" da população? Antes de qualquer coisa, é fundamental observá-la em busca de processos recorrentes, em busca de uma normalidade. Procurar a normalidade é abdicar na normatização - como fazia e faz o poder disciplinar - em nome da identificação das variáveis que impactam, naturalmente, sobre as dinâmicas da população. Em outras palavras, de nada adianta tentar mudar a população, será apenas factível in- 
cidir sobre seu desenvolvimento no tempo e no espaço, estimulando constantes preexistentes através de tecnologias sociais adequadas. Qual é o vetor principal da dinâmica populacional? O desejo dos indivíduos - suas volições - , responderiam os fisiocratas ${ }^{6}$ :

a naturalidade do desejo marca a população e a técnica governamental pode penetrá-lo - esse desejo (...) é tal que, se ele agir ou se se o deixar agir dentro de determinados limites e em virtude de uma série de relações e conexões, redundará, em suma, no interesse geral da população (Foucault, 2006, p. 96).

Saberes especializados se encarregarão de medir as "normais" da população e será o governante quem, através do dispositivo de segurança, irá introduzí-las no horizonte de sua estratégia política. A articulação entre conhecimentos técnicos e poder político é o que garante a produção de riquezas, a potencialização da liberdade dos indivíduos e o bom funcionamento da economia. A liberdade é uma categoria indissociável do debate conceitual sobre o dispositivo de segurança:

Um dispositivo de segurança (...) só pode funcionar bem com a condição de que ocorra algo que é justamente a liberdade, no sentido moderno que esta palavra adota no século XVIII: já não as concessões e os privilégios associados a uma pessoa, mas sim a possibilidade de movimento, deslocamento, processo de circulação da gente e das coisas. E é essa liberdade de circulação no sentido amplo da expressão, essa faculdade de circulação, que é central entender (...) (Foucault, 2006, p. 71).

Como conceber a liberdade e, mais do que isso, como criá-la,

\footnotetext{
${ }^{6}$ Modernidade ocidental e capitalismo estão fundidos (Santos, 2010b, p. 522) desde o século XVIII em uma matriz global de poder que muitos autores denominam sistema-mundo. Jorge Luis Acanda constata que o ato de controlar a ação do sujeito para inserí-la nos marcos pugnados por uma estratégia política determinada passa, necessariamente, por mecanismos de coerção. A novidade da modernidade capitalista - arraigada ideologicamente na ênfase fisiocrática sobre a busca individual de interesse como vetor da dinâmica de populações - é que a coerção política (e, por que não, biopolítica) tornou-se coerção econômica, via "necessidade de conseguir dinheiro visando à aquisição de bens indispensáveis para a sobrevivência" (Acanda, 2006, p. 53).
} 
multiplicá-la nos marcos de uma racionalidade política que valoriza a produção e a circulação incessante de coisas e de pessoas? Eis a grande questão colocada à governamentalidade. A resolução de tal problemática depende de dois procedimentos, dois objetivos encadeados, um de ordem epistemológica e outro de cariz pragmático: primeiro há que estabelecer as grandes tendências que devêm da livre escolha dos sujeitos sob determinadas condições; em segundo lugar, há que fixar os marcos nos quais a liberdade pode fluir de modo a otimizar os aspectos desejáveis da natureza da população.

Para cumprir com o primeiro dos objetivos, um leque de saberes especializados - a demografia, a economia política, a estatística - terá de estabelecer o normal e o anormal no conjunto de determinada população. Tanto a normalidade quanto a anormalidade são características "naturais" de uma dada concertação de fenômenos; contudo, se elas forem medidas acuradamente pelas técnicas correspondentes, poderão servir como substrato para a intervenção do dispositivo de segurança, que se encarrega de cumprir o segundo objetivo mencionado. A "normalização" é, em si, o próprio dispositivo de segurança. Explico. De posse dos gradientes de normalidade (das "normais", num acepção estatística) criadas pelos saberes que se debruçam sobre o estudo da natureza das populações, o dispositivo de segurança estará habilitado para atuar no sentido de promover a assimilação das atribuições desfavoráveis pelas favoráveis.

A motivação de normalização diferencia o dispositivo de segurança do dispositivo disciplinar. Este último impõe normas a priori (e não "normais") através das quais se distingue o normal do anormal. Por sua vez e em última instância, "segurança" é um dispositivo de controle das populações que persegue a anulação [do anormal] no elemento da realidade. Por realidade devemos entender "nível de realidade", ou seja, uma secção perpetrada pelo saber-poder no âmbito do real. Para resumir as diferenças entre poder soberano, poder disciplinar e segurança, recorro, uma vez mais, às palavras de Foucault:

(...) a lei proíbe, a disciplina prescreve e a segurança, sem proibir nem prescrever, e ainda que, eventualmente, lance mão de alguns 
instrumentos vinculados com a interdição e a prescrição, tem a função essencial de responder a uma realidade de tal forma que a resposta anule, limite, freie, regule essa realidade. Esta regulação no elemento da realidade é, penso, o fundamental nos dispositivos da segurança. (Foucault, 2006, p. 69)

A segurança não controla, não cerceia, não restringe como fazia e faz a disciplina. Tampouco se centra no mercado e em tudo aquilo que supostamente o rodeia. Pelo contrário, a segurança consiste numa forma de apreender e governar a vastidão de fenômenos do mundo ${ }^{7}$. Sua contrapartida não é o soberano, mas sim a arte de governar. Sua preocupação não aninha apenas nos indivíduos e nas redes de intercâmbio mercantil que eles estabelecem, ela estende-se ao novo âmbito da economia e do mercado mundial, buscando integrar e ordenar tantas variáveis quanto seja possível imaginar (psicologia individual, comportamento dos produtores, dos compradores, dos consumidores): trata-se, portanto, de organizar ou, em todo caso, de permitir o desenvolvimento de circuitos cada vez maiores (Foucault, 2006, p. 67). Por detrás do dispositivo de segurança, podemos antever uma espécie de fatalismo otimista: as "coisas" dão-se de acordo com suas próprias regras, é ilusório ambicionar mudá-las; não obstante, será possível governar as "coisas" se conhecermos quais regras gerais controlam seu movimento e sua transformação no tempo e no espaço. ${ }^{8}$

\footnotetext{
${ }^{7}$ Durante a época de vigência da governamentalidade liberal, a grande questão colocada aos governantes e aos teóricos da arte de governar era: até onde deve estender-se o aparelho de governo e onde deve cessar a regulação? No período neoliberal a questão inverteu-se: como transpor as leis da economia para a gestão do aparelho de governo? Em todo caso, o pressuposto de fundo segue o mesmo: existem espaços fenomênicos (a população, a economia) cruzados por leis cuja apreensão através de saberes especializados garantirá o bom governo.

${ }^{8}$ Segundo Foucault, a governamentalidade moderna assume com mais nitidez, a partir do século XIX, as feições de uma biopolítica baseada no poder de "fazer viver e deixar morrer". A possibilidade de emergência da biopolítica e do bipoder é o próprio dispositivo de segurança e seu correlato, a população. Teço alguns comentários sobre bipolítica e migração em Moraes (2011).
} 


\section{GOVERNO DAS POPULAÇÕES E DESLOCAMEN- TO DE PESSOAS}

As "coisas" das quais o governo de populações encarrega-se são seres humanos. Seres humanos inseridos num campo de variáveis materiais, que não são riquezas, mas "recursos", meios de subsistência, o território em suas fronteiras, com suas qualidades, clima, seca, fertilidade, etc. O governo diz, pois, respeito às coisas entendidas como a imbricação de homens e coisas dispostas em um âmbito de atuação que engloba, virtualmente, o mundo (Foucault, 1999a, p. 282).

Com efeito, o problema do governo, de como governar e ser governado, adquirira notável relevância no pensamento político do século XVI, justamente quando a centralização política começara a restar espaço à divisão feudal dos territórios e as navegações ultramarinas agregaram extensos domínios coloniais aos estados europeus, exigindo-lhes uma permanente preocupação administrativa. No entanto, é partir de finais do século XVIII, com a emergência de uma ordem mundial encabeçada por estados-nação imperialistas, que a preocupação com o estrito controle das populações investirá a relevância que hoje em dia possui. As razões para isto são variadas. Pode-se, contudo, dizer que elas radicam, fundamentalmente, 1) na necessidade desses estados de garantir não apenas a produção de riquezas e o ajuste da vida humana às condições da produção, mas também a distribuição seletiva (primeiro entre os colonos em oposição às populações nativas, depois entre os "nacionais" em oposição aos "estrangeiros") e hierarquizada de recursos e benefícios; 2) na preocupação com a unidade e homogeneidade racial e ideológica da nação; 3) na manutenção de grandes exércitos e extensas aparelhagens burocráticas; 4) na necessidade de demarcação das fronteiras coloniais, povoamento das colônias e assujeitamento das populações nativas.

Uma das facetas emblemáticas do controle de populações no Estado moderno - e aquela que interessa especialmente aos objetivos deste artigo - consiste no que o sociólogo estadunidense John Torpey (2003) denominou monopólio dos meios de circulação legítimos. Ou seja, o processo de crescente concentração, nas mãos do 
Estado, daqueles mecanismos que possibilitam o deslocamento das pessoas no interior dos seus territórios e para além deles.

Ao propor uma sociologia histórica, Torpey resgata, no livro $A$ Invenção do Passaporte, a trajetória deste documento-símbolo da geopolítica moderna. $\mathrm{O}$ autor demonstra-nos que a origem do passaporte remonta à Europa absolutista, quando servia para controlar os deslocamentos dos súditos no interior dos limites dos reinos. A conversão do passaporte em documento aceito internacionalmente teve lugar somente no século XIX, quando a hegemonia dos Estados-nação era incontestável e os diversos projetos de centralização política haviam atingido seus fins estratégicos. Da mesma forma que o monopólio do uso legítimo da força, o monopólio dos meios de circulação legítimos seria condição sine qua non para a existência do Estado moderno. $\mathrm{O}$ passaporte, por sua vez, garantiria este monopólio e, dada sua generalização para todos os países existentes, consolidaria o reconhecimento recíproco das soberanias nacionais no marco de uma comunidade internacional. Mais do que isso, o passaporte - e os documentos de identificação de uma maneira geral - apareceriam como as ferramentas privilegiadas da estratégia de controle estatal das populações ${ }^{9}$. Numa passagem inspirada, Torpey afirma o seguinte: (...) os documentos de identificação de vários tipos constituem o equivalente burocrático do dinheiro: eles são a moeda da moderna administração estatal (Torpey, 2003, p. 31). De fato, para se ter acesso a quaisquer benefícios disponibilizados pelo Estado, não basta existir, é preciso dispor de documentos. Em outro lugar (Jardim; Moraes, 2011) sugeri que os estados só enxergam através de documentos. A metáfora proposta por Torpey, no entanto, parece mais atraente, porque sinaliza que a ausência de documentos não invisibiliza os indivíduos, mas, pelo contrário, visibiliza-os negativamente, excluindo-os, como escreveu Hayman (1995), das normas de gentileza e receptividade que se reservam aos membros de uma comunidade.

\footnotetext{
${ }^{9}$ Ao longo do seu texto, Torpey utiliza de forma algo imprecisa o conceito de população, justapondo-o à noção de sociedade. Mais adiante, neste tópico, tencionarei tal sobreposição, sugerindo que reservemos a ideia de população para aludir ao sujeito-coletivo de uma estratégia de poder e utilizemos a ideia de sociedade para evocar um espaço conflitivo onde os jogos de poder incidem sobre a produção dos sujeitos.
} 
Outro desdobramento interessante do aforismo que relaciona documentos e moedas é o fato concreto de que documentos custam dinheiro. Pode-se converter dinheiro em documentos tanto por vias oficiais/legais, quanto por vias extra-oficiais e, portanto, ilegais. Finalmente, há situações onde a transferência de recursos financeiros por parte do Estado aos seus cidadãos ocorre mediante apresentação de documentos. Nestes casos, existe um constrangimento econômico concreto para que o indivíduo obtenha papeis, preencha formulários, receba visitas sociais, etc., de forma a figurar como beneficiário de programas de capitalização.

Ressaltadas algumas dimensões potentes da matriz conceitual elaborada por Torpey, quero, agora, sinalizar certas imprecisões que, se desconsideradas, podem diminuir o fôlego de uma problematização teórica acerca dos mecanismos de controle das populações. Centro-me, primeiramente, num dos pontos altos da reflexão do autor, quando ele sugere que os documentos de identificação respondem à necessidade dos estados de "envolver" as populações/sociedades ${ }^{10}$ para "penetrá-las" com mais facilidade. Neste momento, Torpey está tencionando com os paradigmas que denomina "penetracionistas", responsáveis pela imagem tradicional (e indiscutivelmente sexual) das sociedades a serem "penetradas" pelo Estado (Torpey, 2003, p. 31). Segundo Torpey, a alusão à penetração diz pouco sobre como os estados conseguem manter relações duradouras com seus súditos ${ }^{11}$, relações estas que constituem a "base social" da sua [do Estado] reprodução (Torpey, 2003, p. 31).

Para Torpey, a metáfora da penetração guarda relações com os interesses (ideológicos?) do próprio Estado, que quer evitar que vislumbremos o quanto ele é capaz de reconfigurar a vida social e, por

${ }^{10}$ Torpey utiliza, novamente aqui, de maneira intercambiada estas duas noções. Minha crítica tratará de demonstrar que é preciso dissociá-las.

${ }^{11}$ Entendo que a categoria "cidadão" descreve melhor o conjunto de indivíduos expostos às normativas nacionais e investidos - idealmente - da possibilidade de reivindicar direitos e disputar os recursos do Estado. A ideia de súdito remete, com muita veemência, a um tipo de relação hierárquica característica do poder soberano e encobre certos fundamentos ideológicos subjacentes à nacionalidade e à cidadania que alimentam a reprodução das hegemonias nacionais sob um regime de distribuição estruturalmente desigual dos bens e dos recursos. Em Moraes 2011, evoco o conteúdo ideológico da ideia de cidadão e procuro situá-lo frente ao dilema contemporâneo da imigração indocumentada.

127| Século XXI, Revista de Ciências Sociais, v.2, nº 2, p.113-148, jul./dez. 2012 
isso mesmo, desvia nossa atenção para o seu crescimento sobre uma sociedade isolada e, supostamente, prostrada aos seus pés. Apontadas as limitações do "penetracionismo", Torpey pergunta-se: como é que as pessoas que constroem a sociedade são obrigadas a "dar a César o que é de César”? Vem, em seguida, um modelo alternativo: estou convencido de que faríamos bem em encarar os estados como entidades que não só procuram penetrar como tentam envolver as sociedades, cercando e apoderando-se dos seus membros (...) (Idem). A imagem do "envolvimento" supera, segundo Torpey, a de "vigilância", descrita por Foucault, posto que este último autor nunca teria sido capaz de explicitar a que fins serve a operação de vigiar.

Diante da crítica à Foucault, é suficiente dizer que a "vigilância" compete ao dispositivo disciplinar de poder, centrado, como discuti mais acima, no controle do corpo do indivíduo e associado ao desejo soberano que fiscalizar a ação de cada um dos seus súditos onde quer que eles estejam. Longe que carecer de sentido, a vigilância correlaciona-se diretamente com os aparelhos de produção e prima pela docilização de corpos e pela sua inclusão ortopédica nos mais diversos espaços de (re)produção social (fábricas, escolas, cárceres, etc.). No entanto, ao falar sobre Estado moderno (especificamente depois da segunda metade do século XVIII), Foucault sublinha que o correlato emergente do governo passa a ser a população, da mesma forma que o correlato da soberania era o sujeito de direitos e a contraparte da disciplina eram os corpos passíveis de prestações.

A noção de população, identificada por Foucault no cerne da governamentalidade moderna, enfraquece a ideia tão material quanto abstrata de sociedade como objeto de poder proposta por Torpey. O Estado não abraça a população para depois penetrá-la. O Estado cria a população através de tecnologias de controle engendradas e promovidas a partir da sua institucionalidade. No âmago dos discursos de saber-poder coagulados em determinadas instituições do Estado, a população aparece já como lócus de intervenção, ela consiste numa dimensão do real recortada de antemão pelo próprio ânimo de governo. É impossível governar e normalizar as condutas antes do seu recorte assim como, depois dele, já não se trata de penetrar, 
mas sim de assujeitar, ou seja, de estimular um conjunto de relações "ideais" entre seres humanos e coisas (recursos materiais, fronteiras, modos de vida, serviços e recursos públicos): a isto se resume, me parece, a possibilidade e a finalidade última do governo biopolítico. Para simplificar: nem envolvimento, nem penetração, mas pretensão de assujeitamento como um único e definitivo movimento.

É necessário frisar, aqui, que a pretensão de assujeitamento evocada no parágrafo anterior não suprime - apenas condiciona o espaço de ação vislumbrado pelos sujeitos, introduzindo, no seio da institucionalidade pública, um campo amplíssimo de negociação onde cidadãos e agentes do Estado - burocratas - desempenharão interações assimétricas catalisadas por um léxico jurídico e atravessadas por expectativas e repertórios táticos heterogêneos. Retomo, neste ponto, um contexto etnográfico que pode elucidar as dinâmicas esboçadas. Os interlocutores de minha pesquisa de mestrado ${ }^{12}$, em sua maioria residentes nas cidades gêmeas de Aceguá-Aceguá, situadas sobre a fronteira brasileiro-uruguaia, desenvolvem uma constante circulação transfronteiriça em busca de oportunidades laborais e serviços públicos de todo o tipo. Alheios às contingências da vida local, os estados brasileiro e uruguaio exigem dos sujeitos interessados em receber planos sociais (Bolsa Família no Brasil e Asignaciones Familiares no Uruguai) que fixem residência, obtenham documentos e matriculem os filhos nas escolas e creches do "lado certo" da divisa política, ou seja, em suas respectivas jurisdições territoriais. Isto introduz alguns percalços extras na vida de grupos sociais fronteiriços cuja própria possibilidade de subsistência associa-se ao agenciamento de práticas de deslocamento transfronteiriças. Diante das limitações jurídico-administrativas que resultam de sua circulação binacional, os sujeitos que colaboraram com minha investigação costumavam acionar repertórios táticos que consistem, por exemplo, em transferir a matrícula das crianças para instituições de ensino no país de origem e "tomar emprestado" o endereço de familiares e amigos que lá residem para poder realizar seu cadastro

\footnotetext{
${ }^{12}$ Esta investigação desenvolveu-se entre julho 2011 e setembro 2012, enfatizando as dinâmicas de trabalho, deslocamento e indocumentação em cidades e povoados localizados na fronteira territorial entre Brasil e Uruguai.
} 
junto aos órgãos responsáveis pela concessão de benefícios sociais. Vislumbramos, aqui, uma possibilidade de reação que impugna, parcialmente, a pretensão de assujeitamento esgrimida pelos estados. No caso da fronteira brasileiro-uruguaia, esta pretensão baseia-se na premissa de que, em se tratando de sujeitos pobres e fronteiras políticas, a conduta supostamente "normal" deveria ser o sedentarismo e o uso exclusivo dos serviços públicos disponibilizados no território do Estado-nação do qual se é cidadão.

Analisemos, agora, o enquadramento geográfico do estudo de Torpey, atentando para a forma como ele justifica sua escolha metodológica. Este procedimento me permitirá explicitar, com referência ao debate descolonial, outros aspectos problemáticos da argumentação desenvolvida pelo autor. Palavras de Torpey:

O enquadramento geográfico do estudo decorre da minha convicção de que o predomínio dos estados ocidentais no período em análise foi relativamente bem definido e que a imposição dos métodos ocidentais na maior parte dos outros países do mundo foi uma das características mais importantes desta época. (Torpey, 2003, p. 14).

O que Torpey quer dizer com "predomínio dos estados ocidentais"? Conjeturo que se refira à expansão colonial europeia e à ampliação da sua aparelhagem administrativa estatal (criação de conselhos ultramarinos, sesmarias, vice-reinados, estruturas produtivas locais, autorização de missões religiosas, etc.) de forma a assegurar a dominação colonial. Se este for o caso, seria possível assinalar que a escolha do universo documental com o qual trabalhou o autor contém um viés eurocêntrico e precisaria ser alargada.

Em que consiste um método de controle? Lançando mão do arcabouço teórico desdobrado até aqui, poderia dizer que consiste na mobilização simultânea de uma lógica de abordagem destinada a regular certo nível de realidade (a população, a economia, por exemplo) e de uma ação concreta orientada à ingerência política neste mesmo nível de realidade. Pois bem, se a circulação de pessoas e coisas torna-se uma questão generalizada de governo, principalmen- 
te a partir do século XVIII, então qualquer análise que se abstenha de supor que as tecnologias cotadas para respaldar o governo das populações guardam relação com a experiência colonial europeia é, no mínimo, imprecisa. Os métodos de controle ocidentais não só foram impostos à maioria das regiões do mundo, senão que se engendraram nas relações da Europa com essas regiões "outras" do globo em meio aos percalços suscitados pelo avanço colonial ${ }^{13}$. Um eurocentrismo análogo àquele que atravessa o recorte metodológico de Torpey já aparece em Weber, quando seus escritos deixam transparecer certo deslumbre diante da perfeição racional das burocracias modernas que emergem na sociedade capitalista de massas do ocidente. Em Cultura e Imperialismo, Edward Said fazia um alerta que poderíamos transpor com exatidão, da crítica literária para a crítica teórico-epistemológica em ciências sociais e humanidades: (...) muitas das características mais importantes da cultura modernista, que costumamos considerar derivadas da dinâmica puramente interna da sociedade e da cultura ocidentais, inclui uma reação às pressões externas do "imperium” sobre a cultura (Said, 1993, p. 299). Santiago Castro-Gómez é ainda mais enfático neste sentido: o surgimento dos estados nacionais na Europa e na América durante os séculos XVII e XIX não é um processo autônomo, senão que possui uma contraparte estrutural: a consolidação do colonialismo europeu em ultramar (Castro-Gómez, 2011, p. 170).

\footnotetext{
${ }^{13} \mathrm{O}$ caso da introdução do sistema de impressões digitais é exemplar desta colonialidade intrínseca às tecnologias ocidentais de governo, uma vez que nela encontramos um movimento de apropriação e readaptação de métodos de identificação individual que já vinham sendo utilizados pelos povos da Índia antes mesmo da chegada dos colonizadores ingleses. Funcionário de "Sua Majestade", o administrador do distrito de Hooghly, em Bengala, Willian Herschel, vinha observando, desde meados do século XIX, que os nativos da região utilizavam as marcas das mãos como uma espécie de assinatura em certas prestações sociais. Herschel decidiu introduzir o método no sistema de distribuição de pensões do governo colonial com o objetivo de evitar fraudes e concessão indevida de benefícios. Pela primeira vez, um método de identificação era utilizado com fins civis, e não criminais, de forma a racionalizar o uso dos recursos públicos. Mais tarde Galton sugerirá a extensão desse método para toda a França em substituição a identificação antropométrica que Bertillon desenvolvera para controlar os criminosos reincidentes. Uma tecnologia utilizada para vigiar o outro colonial "viaja" à Europa para converter-se em ferramenta de controle dos "outros" internos à sociedade capitalista emergente. Para um debate mais detalhado sobre identificação e colonialismo, ver Cole (2001) e Ginzburg (1990).
} 
Os estudos sobre burocracia, racionalização e controle, por vezes incidem num imaginário eurocêntrico que projeta a Europa como âmbito territorial isolado que constituiu métodos de controle societário a partir de tensões endógenas e sem contato algum com outras culturas: racionalização, no sentido weberiano, teria sido resultado de um desdobramento de qualidades inerentes às sociedades ocidentais (o deslocamento em direção à modernidade), e não da interação colonial da Europa com América, Ásia e África a partir de 1492 (Idem).

Finalizo minha revisão crítica dos argumentos de Torpey avaliando de que maneira este autor interpreta o sentido estratégico da ação controladora do Estado sobre a circulação de pessoas. Esta questão me levará a introduzir o terceiro eixo de debate do presente trabalho - construção de alteridades - que, por sua vez, será desenvolvido com algum detalhamento no seguinte tópico.

Torpey sugere que os estados agarram as sociedades para conseguir concretizar seus objetivos, ou seja, obter os recursos que o Estado necessita para sobreviver e se reproduzir ao longo do tempo. Torpey não define claramente quais são as fontes específicas de onde o Estado extrai os recursos necessários à sua reprodução, mas não é difícil depreendê-las: o fisco; a guerra (principalmente no caso dos estados imperialistas); a força de trabalho e as forças produtivas (seja através da taxação da produção ou da exploração direta dos trabalhadores em empreendimentos produtivos estatais). Se bem a interpretação do autor é descritiva de uma das motivações que impulsiona o controle sobre a circulação de cidadãos e não-cidadãos, ela carece de amplitude e omite um dos aspectos essenciais daquilo que o próprio Torpey classifica como "governação", a saber, a necessidade de ajustar os seres humanos ao aparelho de produção (e não apenas de lhes extrair os recursos para reprodução do aparelho de Estado).

Ao falar em alocação de recursos por parte do Estado sem mencionar de que maneira este garante que ocorra a produção dos recursos, o autor omite todo um sistema de relações no qual a classificação social atua para fazer valer concretamente as linhas divisórias entre os nacionais e os não-nacionais, quer [fora das] fronteiras físicas [do Estado], quer entre as pessoas que se encontram 
no interior destas (Torpey, 2003, p. 16). Quando Torpey afirma que o monopólio do uso legítimo da violência foi tão importante para a conformação do Estado moderno quanto o monopólio dos meios de circulação legítimos, falta-lhe agregar uma complementação como a levantada por Santiago Castro-Gómez: o Estado moderno não adquire somente o monopólio da violência, ele também se utiliza dela para "dirigir" racionalmente as atividades dos cidadãos, de acordo com critérios estabelecidos cientificamente de antemão (Castro-Gómez, 2011, p.165). Esta ponderação é fundamental em nossa análise porque possibilita que identifiquemos no Estado moderno uma máquina de produção incessante de outridades hierarquizadas sem as quais nem ele nem todo o regime geral de governamentalidade poderiam existir. O monopólio dos meios legítimos de circulação não é apenas homólogo do monopólio do uso da violência, é, também, um correlato dele. E aqui entramos, novamente, em sintonia com Torpey, corroborando-o em sua afirmação de que o Estado é muito mais do que uma "estrutura de ideias". É também (...) uma rede mais ou menos coerente de instituições. E mais adiante: as identidades têm de ser codificadas e institucionalizadas para se tornarem importantes em termos sociais (Torpey, 2003, p. 34-35). Sublinhemos, desta afirmação, a ideia de "importância em termos sociais". Ora, esta importância consiste, nada mais, no lugar simbólico-estrutural que se procura conferir aos indivíduos e grupos no elemento dos conflitos, segmentações e contradições que dão forma ao mundo social ${ }^{14}$. A produção efetiva do outro só adquire materialidade no elemento do social, porque é nele que incidirão sobre os sujeitos as coerções (materiais e simbólicas) concretas associadas ao princípio de governo. É na sociedade, portanto, que a diferença faz-se corpo e se torna significativa (comumente sob a forma de desigualdade).

Para a coletividade de argumentação "modernidade-colonialidade", a colonialidade do poder descreve uma modalidade de classificação de todos os povos do mundo surgida no século XVI e assente

\footnotetext{
${ }^{14}$ A condição social dos sujeitos configura-se na justaposição das estratégias de governo das populações e na capacidade daqueles de negociar - confrontados com variáveis que não escolheram - sua posição no lance-a-lance das táticas cotidianas. 
na formação racial, no controle do trabalho, no Estado ${ }^{15}$ e na produção de conhecimento (Grosfoguel, 2010, p. 414). Daí resulta a importância de identificar sem ambiguidade (Torpey, 2003) umas pessoas das outras: é essencial produzir "outros". A outrificação dos sujeitos não é efeito colateral da ação escrutinadora e seletiva do Estado para fins de obtenção dos "recursos para sua reprodução". Trata-se, na verdade, de um objetivo inscrito na própria matriz da governamentalidade moderna. A modernidade ocidental baseia-se em linhas de pensamento abissais ${ }^{16}$ que produzem uma epistemologia binarista insensível às ambiguidades, hibridações, multiplicidades, em fim, aos fenômenos que constituem a materialidade emergente do mundo.

\section{PRODUÇÃO DE ALTERIDADES}

A aventura colonial europeia e o projeto global do imperialismo e do colonialismo generalizaram a divisão abissal entre Norte e Sul do mundo (Santos, 2010a). A conversão dessa divisão abissal em condição epistemológica de conhecimento e intervenção na realidade caracteriza a maioria dos mecanismos de produção de alteridades instituídos pela ordem jurídica dos Estados-nacionais. Em que consistem essas linhas abissais das quais nos fala Boaventura de Sousa Santos? Elas consistem numa forma de organização do pensamento que esquadrinha a diversidade de elementos do mundo social segundo parâmetros absolutos, colocando aquilo que é visível de um lado e aquilo que é invisível de outro. Neste sistema, as distinções invisíveis fundamentam as visíveis: a divisão é tal que o outro lado da linha desparece como realidade, torna-se inexistente e é mesmo produzido como inexistente (Santos, 2010a, p. 32). Em outras palavras, só existe aquilo que responde positivamente à pretensão de assujeitamento mobilizada pelas tecnologias de poder e controle.

\footnotetext{
15 Reparemos que, na perspectiva da colonialidade do saber-poder, o Estado é parte de uma malha de controle, ou seja, está abarcado por essa malha que também orienta o funcionamento de outras instituições. O Estado erige-se como lócus fundamental - mas não único - de elaboração de classificações potentes.

${ }^{16}$ A operatória das linhas de pensamento abissais (Santos, 2010a) como condição epistemológica do processo de construção de alteridades desencadeado pela racionalidade moderna será abordada no terceiro tópico.
} 
O imperialismo valeu-se largamente dessas distinções para articular estratégias de dominação e exploração nos territórios onde se expandiu. A razão imperialista não é um efeito secundário da existência de Estados-nacionais. Ela é um elemento fundante das nações modernas. A hegemonia nacional baseia-se num imperialismo para dentro, apontado à dissolução de todo "ruído" que possa colocar em cheque a pretendida homogeneidade da comunidade imaginada, e num imperialismo para fora, ancorado no neocolonialismo, que vem a reboque a extrema concentração de capital no Norte global. As amity lines do século XVI são, talvez, o primeiro exemplo da cartografia abissal. Através delas, as potências imperiais dividiam o território do mundo entre zonas onde deveria reinar a paz e a amizade e zonas alheias a qualquer legalidade, onde todo tipo de arbitrariedade e violência (saque, pirataria) era aceito ${ }^{17}$. O elaborado trabalho cartográfico investido na definição e representação das amity lines exigia extrema precisão aos cartógrafos, fabricantes de globos terrestres e navegadores. Tais preocupações viam-se, também, refletidas em um policiamento vigilante e nas duras punições das violações. Na sua constituição moderna, o colonial representa não o legal ou o ilegal (reservados apenas para o lado visível da linha), mas o sem lei, o que está, ainda, por ser domesticado e enquadrado nos marcos civilizacionais. Estas cartografias modernas, produtoras de linhas divisórias mundiais, incidem sobre as formas de exercício do poder em escala global. Nelson Maldonado-Torres comenta que

quando os mappae-mundi medievais passam a Orbis Universalis Christianus, ocorre uma significativa mudança na concepção dos povos e do espaço. À medida que iam sendo desenhados os mapas, descritos os povos e estabelecidas as relações entre conquistadores e conquistados, foi emergindo um novo modelo de poder. (Maldonado-Torres, 2010, p. 414)

\footnotetext{
${ }^{17}$ Boaventura de Souza Santos indica que a primeira amity line poderá ter emergido do Tratado de Cateau-Cambresis (1559) entre Espanha e França (...) Deste lado da linha vigoram a verdade, a paz e a amizade; do outro lado da linha, a lei do mais forte, a violência e a pilhagem. O que quer que ocorra do outro lado da linha não está sujeito aos mesmos princípios éticos e jurídicos que se aplicam deste lado. (...) Esta dualidade permitiu (...) aos reis católicos da França manterem, deste lado da linha, uma aliança com os reis católicos da Espanha e, ao mesmo tempo, aliarem-se aos piratas que, do outro lado da linha, atacavam os barcos espanhóis (Santos, 2010a, p.36). 
Este modelo de poder consiste em um sistema de classificação onde as pessoas são ordenadas segundo três linhas diferentes, mas articuladas numa estrutura global pela colonialidade do poder: trabalho, raça, gênero (Quijano, 2007, p. 115). Tais linhas, por sua vez, articulam-se ao redor de dois eixos centrais:

controle da produção de recursos de sobrevivência social e controle da reprodução biológica da espécie. O primeiro implica o controle da força de trabalho, dos recursos e produtos do trabalho, o que inclui os recursos "naturais" e se institucionaliza como "propriedade". O segundo implica o controle do sexo e dos seus produtos (prazer, descendência), em função da propriedade. A "raça" foi incorporada no capitalismo eurocentrado em função de ambos os eixos. E o controle da autoridade organiza-se para garantir as relações de poder assim configuradas. (Quijano, 2007, p. 115)

Penso ser pertinente tomar os três eixos de que nos fala Quijano como vetores estratégicos de poder orientados ao governo das populações. Estes vetores operam em conjunto com as três linhas anteriormente mencionadas e introduzem no real um gradiente estruturante e estruturado de alteridades hierarquizadas e, frequentemente, separadas por linhas abissais.

Foucault contribuiu enormemente para a compreensão de como o poder é exercido no capitalismo, mas escreveu pouco sobre as fontes desse poder. Ele, sem dúvidas, jamais negou que os poderes disciplinares pudessem ser agregados às estratégias estatais e aos interesses econômicos da burguesia, mas a maioria dos seus estudos partia de técnicas relativamente autônomas de poder e de exclusão para então compreender como elas puderam ser generalizadas, porque puderam despertar o interesse político e econômico de uma determinada classe social (Duarte, 2008, p. 55). Seja como for, é impossível não reconhecer que, se o poder é ubíquo, como nos sugeria Foucault, a desigualdade também o é. A noção foucaultiana de poder disciplinar - de cujas técnicas o dispositivo de segurança vale-se para agir na população mediante controle das volições dos 
indivíduos - pode ser corrigida e ampliada, como sugere Santiago Castro-Gómez (2011), pelo conceito de colonialidade do poder. Este conceito coloca em relevo o fato de que os dispositivos panóticos erigidos pelo Estado moderno se inscreve[m] em uma estrutura mais ampla, de caráter mundial, configurada pela relação colonial entre centros e periferias em razão da expansão europeia (Castro-Gómez, 2011, p. 171). Sem o aparecimento de um mecanismo global de poder, a existência do Estado-nação moderno, tal como o conhecemos, não seria viável, posto que a a manutenção do poder de um Estado não pode prescindir da sua relação conflitiva com outros Estados (idem). O encadeamento de todas essas formas de exercício do poder, de todas essas artes de governar, dá os contornos de uma totalidade heterárquica dividida em vários níveis, cada qual caracterizado pela vigência de formas específicas de assujeitamento e hierarquização. Esta totalidade heterárquica onde os diferentes poderes agem, tencionam e se intersectam, permitindo e promovendo a produção constante de alteridades, é o sistema-mundo patriarcal/ capitalista/moderno europeu. Santiago Castro-Gómez apresenta esquematicamente este campo de forças como estando composto por:

um nivel microfísico no qual operariam as tecnologias disciplinares e de produção de sujeitos, assim como as "técnicas de si", que buscam uma produção autônoma da subjetividade; um nivel mesofísico no qual se inscreve a governamentalidade do Estado moderno e seu controle sobre as populações através da biopolítica; e um nivel macrofisico onde se localizam os dispositivos supraestatais de segurança que favorecem a "livre competição" entre os Estados hegemônicos pelos recursos naturais e humanos do planeta. Em cada um destes três níveis o capitalismo e a colonialidade do poder se manifestam de forma diferente (Castro-Gómez, 2007, p. 162). Em itálico no texto original.

Os níveis molares da cadeia de poder (nível mesofísico [ou semi-global] e macrofísico [global]) derivam dos níveis moleculares. As estruturas mais complexas originam-se das estruturas menos complexas. Como procurei demonstrar ao longo de minha argumentação, o 
nível microfísico associou-se, historicamente, ao nível mesofísico das técnicas de governo a partir do século XVIII, quando a população apareceu como objeto privilegiado do poder estatal, contudo

não há nenhum imperativo estrutural que determine a necessidade deste vínculo. A princípio são duas cadeias distintas por onde o poder circula de forma diferente, mas cujo vínculo pode romper-se a partir das técnicas de si, que são as que podem impedir, em última instância, que a normalização e a biopolítica se in-corporem, se façam corpo (Castro-Gómez, 2007, p. 166).

O controle da circulação de pessoas e os mecanismos de poder a ele associados atuam no nível mesofísico, que sofre forte ascendência da moderna racionalidade de Estado (uma razão notadamente imperial), calcada em linhas de pensamento abissal. Esta esquematização ajuda-nos a compreender porque o debate atual sobre migrações contemporâneas nos países do Cone Sul gira em torno do problema da visibilidade do imigrante. De acordo com cada conjuntura nacional, o sujeito que migra é representado como alguém mais ou menos visível, ao sabor das normativas vigentes e dos discursos hegemônicos em voga a respeito dos mercados de trabalho, da economia e da situação infraestrutural do Estado. De qualquer forma, mesmo quando os imigrantes são visibilizados pelo discurso de poder, este parece tratá-los como uma alteridade problemática, algo que, pelo simples fato de existir, é, em si, um inconveniente. Esta tendência do poder estatal à exclusão ocorre porque, ainda quando a realidade dos processos migratórios na região do Cone Sul apresenta variáveis nem sempre observadas nos deslocamentos SulNorte, de forma análoga, nos dois hemisférios, o debate em torno do "problema social da imigração" lança mão, em grande medida, das categorias de nacional e não-nacional que originam, por sua vez, a oposição abissal entre cidadãos e não-cidadãos. Os passaportes, os trâmites de concessão da cidadania ou dos vistos de permanência e residência respondem, sempre, à necessidade estratégica de manutenção desta oposição. 
Da divisão radical entre nacionais e estrangeiros decorrem múltiplos percalços que vão constituindo a alteridade imigrante em diferentes espaços da sociedade. Assim, por exemplo, alguns trabalhadores rurais indocumentados que colaboraram com minha etnografia na fronteira entre Brasil e Uruguai veem aprofundada sua subordinação social e econômica quando os Estados nacionais, em ambos os lados do marco fronteiriço, condicionam a distribuição de benefícios sociais à posse de documentos que comprovem regularidade da situação migratória. Sem os documentos, meus interlocutores ficam invisibilizados, tornam-se pobreza exótica (Sayad, 1991) e irresolúvel. Situações deste tipo obrigam-nos a questionar a premissa culturalista de que o sujeito que migra conforma, a priori, minorias étnicas e possui uma "cultura" que determina suas formas de pensar e origina suas dificuldades de integração. Daniel Etcheverry (2009), em diálogo com Abdelmalek Sayad, coloca que, não raro, este tipo de representação estática e unidirecional acerca do que é o imigrante, passa a ser compartilhado pela sociedade de imigração, emigração e pelos próprios imigrantes: tais ilusões procedem, em grande medida, das próprias categorias de pensamento, as quais são, também, categorias sociais, econômicas, culturais e politicas (Sayad, 1991, p.17 apud Etcheverry, 2009).

O drama que caracteriza uma condição social frequentemente compartilhada pelos meus interlocutores na fronteira brasileiro-uruguaia é a impossibilidade de cidadanizar-se ${ }^{18}$. Apesar das políticas comuns de reconhecimento dos direitos cidadãos no Mercosul, muitos trabalhadores, ao empreenderem um deslocamento transfronteiriço, convertem-se em sujeitos sem Estado. O absurdo desta situação trás à tona, com clareza, um tipo de diferença que - a revelia da ideologia multiculturalista da igualdade na diversidade - só pode existir enquanto desigualdade irrevogável e apenas parcialmente negociável. Agamben (2002), refletindo sobre as consequências do poder soberano - que garante a estabilidade jurídica e territorial dos

\footnotetext{
${ }^{18}$ Defino cidadanização como o processo de polarização e tencionamento entre atores sociais desiguais, que se manifesta nas democracias liberais contemporâneas através da linguagem da multiplicação e concessão de direitos.
} 
Estado-nação modernos -, propôs que seu correlato necessário é o homo sacer. Este figura foi definida, no antigo direito romano como

o homem que se inclu[i] na legislação na exata medida em que se encontr[a] totalmente desprotegido por ela (...) Para Agamben, não se pode pensar a figura do soberano sem implicar a figura correlata do Homo sacer, de modo que enquanto houver poder soberano haverá vida nua e exposta ao abandono e à morte (Duarte, 2008, p. 53).

Fora de qualquer jurisdição, o sujeito que migra através da fronteira só conta com seu corpo - vestígio primeiro da concretude de sua humanidade - e, através deste corpo (nem sempre reconhecido pela oficialidade), diferente em primeira instância (posto que estrangeiro, estrangeirizado) e desigual (posto que subordinado ao julgamento que outros farão a respeito da sua utilidade e legitimida$\operatorname{de}^{19}$ ), ele deverá livrar-se ao percurso de reivindicação de algum tipo de benefício da cidadania.

As linhas abissais que orquestram o sistema de classificação operado pela governamentalidade moderna suscitam, então, um tipo bastante específico de alteridade: deste lado da linha, perfilam-se aqueles sujeitos habilitados - apenas idealmente, é certo - para competir de forma legítima pelas reservas de bem-estar social disponibilizadas pelas instituições oficiais; do outro lado da linha, estão os não-cidadãos que, abandonados a própria sorte, deverão contar apenas com o êxito das suas táticas para fazer frente às contingências da vida social. Poderíamos reelaborar este panorama valendo-nos da distinção entre população e povo, proposta por Foucault (2006): de um lado da linha, a população, que se mantém e subsiste num nível ótimo; do outro lado da linha, o povo, que comporta-se como se não fizesse parte desse sujeito-objeto coletivo que é a população, como se agisse à margem dela (Foucault, 2006, p. 65). O povo é o lugar do desajuste, da

${ }^{19}$ José Jorge de Carvalho faz notar que no capitalismo, o indivíduo que não controla os meios de produção faz-se representar, não enquanto sujeito, mas sim enquanto valor de troca. Paradoxalmente, sua legitimidade passa a ser dada por outra persona, que toma seu lugar no espaço público, essencializando-o como o lugar genérico do outro do poder (Carvalho, 2002, p. 300). Do outro lado da divisão abissal, o "outro" do poder fica, portanto, a mercê duma intervenção reificadora que o converterá em elemento "útil”, de acordo com as necessidades da economia e da produção. 
exceção, do "problema social", mas, como em qualquer divisão abissal, é a condição de existência da população, é o elemento contrastivo que ressalta o manejo da população e denuncia as zonas que precisam ser abarcadas pela normalização ou, em caso extremo, abandonadas à própria sorte. A condição de imigrante - principalmente quando articulada com situações "desvantajosas" de classe, raça ou gênero é colonizada, na atual ordem dos Estados-nação, pelas perspectivas abissais que entranham tanto instituições públicas quanto privadas. As linhas abissais materializam-se num sem-número de tecnologias de separação e exclusão, das quais os documentos de identificação como nos demonstram os contextos etnográficos mencionados - constituem indício visível e palpável.

\section{CONCLUSÃO: E O LUGAR DA ETNOGRAFIA?}

O amplo debate proposto neste artigo começou pela discussão do conceito foucaultiano de população, entendida como um nível de realidade recortado pela governamentalidade moderna e inserido na clivagem do poder graças a uma série de dispositivos - alguns preexistentes, outros relativamente novos - de controle e normalização. Num momento subsequente, esbocei paralelos entre a moderna arte de governar e a experiência colonial europeia, procurando sublinhar a interdependência entre ambas e sua incidência matricial na razão contemporânea de Estado. Sugeri, então, que as múltiplas relações e tecnologias de poder delineadas ao longo da exposição operavam de maneira interdependente no espectro de uma totalidade heterárquica que, no argumento descolonial, denomina-se sistema-mundo patriarcal/capitalista/moderno europeu. Concepções disciplinares mais tradicionais poderiam objetar que a evocação desta macroestrutura geopolítica coloca-nos a uma distância considerável daquilo que se concebe como o lugar e o objeto da etnografia. Meu ponto de vista é outro. Acredito que a enunciação teórica de uma totalidade pode redimensionar e mesmo transformar o objeto da etnografia, afastando-a de essencialismos ou reducionismos do tipo "culturas são ilhas" ou 
"capitalismo é uma cultura" 20 que, ainda hoje - e de forma bastante contundente -, preservam intacta a colonialidade intrínseca na construção do conhecimento antropológico. Esta colonialidade manifestase, também, no interior da própria disciplina, através de mecanismos institucionais como as politicas editoriais, a predominância de certas línguas e dos textos escritos, os formatos de argumentação, a sedimentação de genealogias e cânones disciplinares, os processos de formação universitários, etc. (Restrepo, 2007, p. 302).

Onde quer que se posicione geográfico-espacialmente, a etnografia habilita situações de interlocução com um enorme potencial evocativo que não pode ser desperdiçado. O lugar da etnografia orientada à formulação de um saber crítico não se circunscreve aos limites estreitos da "tradicionalidade", da "comunidade", da alteridade radi$\mathrm{cal}^{21}$, etc. Ao contrário, ele aparece como a justaposição de múltiplas escalas de enunciados, discursos, relações de poder. Consiste num lugar iminentemente politizado, precisamente porque, nele, desenvolvem-se as práticas e saberes locais que com tanto afinco os etnógrafos perseguem. As práticas e os saberes são "locais" justamente porque não puderam universalizar-se, porque, muitas vezes, foram produzidos como inexistentes, sem, por isso, perderem vigência, potência e, por conseguinte, capacidade de expressar modos de vida singulares. O esforço da etnografia vai no sentido de garantir às teorias e práticas "localizadas" uma politicidade e uma historicidade que lhes são negadas sistematicamente pelos sistemas de dominação.

\footnotetext{
${ }^{20}$ Este tipo de aforismo dá lugar a um arraigado senso comum disciplinar. Mesmo quando acreditamos ter "relativizado" o conceito de cultura e a noção de "outro", não raro, surpreendemonos fazendo inspiradas exortações à familiarização da diferença e ao estranhamento do familiar. Enunciados desta natureza continuam a obliterar as dinâmicas de produção da diferença, ao mesmo tempo em que se eximem de um debate mais acurado sobre o papel da própria Antropologia - com "a" maiúsculo - no disciplinamento da diversidade e no seu enquadramento em marcos estáticos como "étnico", "comunidade", etc.

${ }^{21}$ Por sua vez, o saber crítico decorrente da etnografia não pode restringir-se a publicação de artigos ou apresentações em congressos, o que converteria a tomada de posições progressistas em mero elemento de distinção e prestígio no âmbito acadêmico. A réplica às manifestações da colonialidade do saber-poder, tanto na antropologia institucional quanto nos contextos etnográficos de nossas pesquisas, tem de ser teórico-epistemológica e política. O olhar etnográfico, como sugere José Jorge Carvalho, precisa explicitar sua politica de alianças com as vozes suprimidas e silenciadas de nossas comunidades (Carvalho, 2002, p. 300).
} 
Arturo Escobar propõe que estendamos nossas pesquisas em direção ao lugar para considerar o impacto que exercem sobre ele questões mais amplas, tais como a relação do lugar com as economias regionais e transnacionais; o cruzamento de fronteiras; o híbrido; $e$ o impacto da tecnologia digital, particularmente a Internet (Escobar, 2011, p. 147). O recorte transversal do presente, além de iluminar uma sucessão de passados e remeter a um contexto espacial muito mais extenso, como escreveu Ginzburg, também nos permite apreender a relação conflitiva entre poderes diversos e desigualmente distribuídos:

a etnografia deveria ser capaz de revelar os diversos campos do discurso em que coexistem declarações oficiais, elucubrações marginais, concepções unanimemente aceitas ou compartilhadas por alguns, enunciados proibidos ou excepcionais e mesmo, muito aquém de tudo o que se pode ouvir, proposições impensadas (Bensa, 1998, p. 52).

As microrrelações enraizadas no lugar - espaço privilegiado do estudo etnográfico - são a forma na qual a modernidade é representada e encenada (Mitchell, 2000, p. xxvi apud Restrepo, 2007, p. 295) efetivamente e não apenas exemplos de resistência a uma modernidade colocada em outro lugar do tempo e do espaço. Estamos falando de modernidades alternativas que tornam a modernidade um terreno de disputas, exigindo dos antropólogos a análise das múltiplas experiências culturais num contexto de globalidade e inter-relação, onde se fragmentam as ficções etnográficas da comunidade e da cultura como unidades metodológicas que se auto contêm e se explicam nos seus próprios termos (Restrepo, 2007, p. 300). A perspectiva heterárquica permite que respondamos a esta exigência, já que ela nos conduz no sentido de um materialismo emergentista que implica múltiplos processos enredados a diferentes níveis estruturais, inseridos numa única realidade material histórica (que inclui o simbólico ideológico como parte dessa mesma realidade material) (Grosfoguel, 2010, p. 474). Para fechar esta já extensa cadeia de citações, retomo Arturo Escobar, para quem: 
construir o lugar como um projeto, converter o imaginário baseado no lugar em uma crítica radical do poder, e alinhar a teoria social com uma crítica do poder através do lugar, exige que nos aventuremos rumo a outros terrenos (...) O saber local não é puro, nem livre de dominação; os lugares podem ter suas próprias formas de opressão e até mesmo de terror; são históricos e estão conectados ao mundo através de relações de poder e de muitas maneiras estão determinados por elas (Escobar, 2011, p. 147).

A busca destas relações, conexões e determinações que conformam a especificidade e a globalidade do lugar consiste no objetivo central do que Marcus (2000) denominou etnografia estrategicamente situada. Sob este prisma metodológico, torna-se possível discutir a coexistência mais ou menos conflitiva de diferentes formas de construção e apropriação do lugar e sua incidência sobre a cultura, a natureza e a economia (Escobar, 2010). A noção de cultura, aqui, já não descreve processos de simbolização atemporais e desindividualizados, ela evoca, isto sim, uma encruzilhada (Restrepo, 2007) transitória de processos multiescalares - cuja dimensão potencialmente global emerge de um jogo de determinações e mediações que vai do micro ao macrofísico - amalgamados sob termos específicos em contextos temporais e espaciais determinados. Adotando este enfoque, penso que podemos evitar tanto o economicismo hierárquico quanto o culturalismo (e outras formas de determinismo cultural), ponderando, cuidadosamente, a influência da justaposição de dinâmicas múltiplas de subjetivação e assujeitamento sobre a realidade contextual de pessoas de carne-e-osso. No plano das relações sociais, referidas dinâmicas podem colocar em choque e interação elementos tão diversos como as práticas e possibilidades individuais de circulação e subsistência, as solidariedades e associativismos variados, o controle estatal sobre as populações, os processos econômicos regionais e transnacionais e as tecnologias globais de segurança que procuram ingerir sobre os fluxos de pessoas, coisas e símbolos no contexto do sistema-mundo capitalista. 


\section{REFERÊNCIAS}

ACANDA, Jorge Luis. Sociedade civil e hegemonia. Rio de Janeiro: Editora UFRJ, 2006.

AGAMBEN, Giorgio. Homo sacer: O poder soberano e a vida nua 1. Belo Horizonte: Editora da UFMG, 2002.

BENSA, Alban. Da micro-história a uma antropologia crítica. In: REVEL, Jacques. Jogos de Escalas - a experiência da microanálise. Rio de Janeiro: Editora da Fundação Getúlio Vargas, 1998. (pp. 39-76).

CASTRO-GÓMEZ, Santiago. Michel Foucault y la colonialidad del poder. Tabula Rasa. no 6, pp. 153-172, 2007.

. Ciencias Sociales, violencia epistémica y el problema de la “invención del otro". In: LANDER, Edgardo. La colonialidad del saber - eurocentrismo y ciencias sociales. Buenos Aires: Fundación Centro de Integración, Comunicación, Cultura y Sociedad - CICCUS; Consejo Latinoamericano de Ciencias Sociales - CLACSO, 2011. (pp. 163-180).

CARVALHO, José Jorge. La mirada etnográfica y la voz subalterna. Revista Colombiana de Antropología. Vol. 38, pp. 287-328, 2002.

DUSSEL, Enrique. 1492: El encubrimiento del otro - El origen del mito de la modernidad. Bogotá, Antropos: 1992.

. Más allá del eurocentrismo: el sistema-mundo y los límites de la modernidad. In: CASTRO-GÓMEZ, Santiago et. al. Pensar (en) los intersticios - Teoría y práctica de la crítica poscolonial. Bogotá: CEJA, 1999. (pp. $147-168)$.

COLE, Simon A. Suspect identities - a history of fingerprinting and criminal identification. Cambridge: Harvard University Press, 2001.

DUARTE, André. Biopolítica e resistência: o legado de Michel Foucault. In: RAGO, Margareth; VEIGA-NETO, Alfredo. Figuras de Foucault. Belo Horizonte: Autêntica, 2008. (pp. 45-56). 
ESCOBAR, Arturo. El lugar de la naturaleza y la naturaleza del lugar: ¿globalización o postdesarrollo?. In: LANDER, Edgardo. La colonialidad del saber - eurocentrismo y ciencias sociales. Buenos Aires: Fundación Centro de Integración, Comunicación, Cultura y Sociedad - CICCUS; Consejo Latinoamericano de Ciencias Sociales - CLACSO, 2011. (pp. 131-162).

. Mundos y conocimientos de otro modo: el programa de investigación de modernidad colonialidad latinoamericano. Revista Tábula Rasa. Vol. 1, no 1, pp. 51-86, 2003.

ETCHEVERRY, Daniel. La Construcción Social del Emigrante: estudio antropológico comparativo de las migraciones en Buenos Aires y Porto Alegre. Iberoamérica Global. Vol 2, nº1, pp.94-112, 2009.

FOUCAULT, Michel. Seguridad, territorio, población - Curso en el Collége de France (1977-1978). Buenos Aires: Editorial Fondo de Cultura Económica, 2007. . Microfísica do Poder. Rio de Janeiro: Graal, 1999. . Em defesa da sociedade - curso no Collège de France (19751976). São Paulo: Martins Fontes, 1999.

GINZBURG, Carlo. Mitos, emblemas, sinais - Morfologia e História. São Paulo: Companhia das Letras, 1990.

GROSFOGUEL, Ramón. Para descolonizar os estudos de economia política e os estudos pós-coloniais: transmodernidade, pensamento de fronteira e colonialidade global. In: SANTOS, Boaventura de Sousa; MENESES, Maria Paula. Epistemologias do Sul. São Paulo: Cortez, 2010. (pp. 455-401).

HEYMAN, Josiah. Putting Power in the Anthropology of Bureaucracy. The Inmigration and Naturalization Service at the México-United States Border. Current Anthropology. Vol. 16, pp. 261-287, 1995.

JARDIM, Denise; MORAES, Alex. O regime de identificação do imigrante na prática: lógicas institucionais de ordenamento e negociação da presença imigrante no Brasil e Uruguai. In: ENCONTRO NACIONAL DA ANPOCS, 35., 2011, Caxambu. Anais do $35^{\circ}$ Encontro Nacional da 
ANPOCS. Caxambu: Anpocs, 2011. p. 1 - 30. In: <http://www.anpocs.org. br/portal/35_encontro_gt/GT22/DeniseJardim.pdf $>$. Acesso em 05 de janeiro de 2012

MALDONADO-TORRES, Nelson. A topologia do ser e a geopolítica do conhecimento. Modernidade, império e colonialidade. In: SANTOS, Boaventura; MENESES, Maria Paula. Epistemologias do Sul. São Paulo: Cortez, 2010. (pp. 396-443).

MIGNOLO, Walter. The darker side of the Renaissance - Literacy, territoriality and Colonization. Ann Arbor: University of Michigan Press, 1995.

. Local histories/global designs. Princeton; University of Princeton Press, 2000.

MORAES, Alex. Experiência social do imigrante, racionalidades econômicas e tensões estruturantes. In: IX REUNIÃO DE ANTROPOLOGIA DO MERCOSUL, 2011, Curitiba. Anais IX Reunião de Antropologia do Mercosul, Curitiba: 2011. p. 1 - 21. In: <http://www.sistemasmart.com.br/ ram/arquivos/ram_GT64_Alex_Martins_Moraes.pdf $>$. Acesso em 05 de janeiro de 2012.

QUIJANO, Aníbal. Colonialidad del Poder y Clasificación Social. In: CASTRO-GÓMEZ, Santiago; GROSFOGUEL, Ramón. El giro decolonial - reflexiones para una diversidad epistémica más allá del capitalismo global. Bogotá: Siglo del Hombre Editores; Universidad Central, Instituto de Estudios Sociales Contemporáneos y Pontificia Universidad Javeriana, Instituto Pensar, 2007. (pp. 93-126).

RESTREPO, Eduardo. Antropología y colonialidad. In: CASTRO-GÓMEZ, Santiago; GROSFOGUEL, Ramón. El giro decolonial - reflexiones para una diversidad epistémica más allá del capitalismo global. Bogotá: Siglo del Hombre Editores; Universidad Central, Instituto de Estudios Sociales Contemporáneos y Pontificia Universidad Javeriana, Instituto Pensar, 2007. (pp. 289-304).

RESTREPO, Eduardo; ROJAS, Axel. Inflexión decolonial - fuentes, conceptos y cuestionamientos. Popayán: Samava, 2010. 
SAID, Edward W. Cultura e imperialismo. São Paulo: Companhia das Letras, 2011.

SANTOS, Boaventura. Para além do pensamento abissal: das linhas globais de uma ecologia de saberes. In: SANTOS, Boaventura de Sousa; MENESES, Maria Paula. Epistemologias do Sul. São Paulo: Cortez, 2010a, (pp. $31-83$ ).

. Um Ocidente não ocidentalista? A filosofia à venda, a douta ignorância e a aposta de Pascal. In: SANTOS, Boaventura de Sousa; MENESES, Maria Paula. Epistemologias do Sul. São Paulo: Cortez, 2010b, (pp. 519-562).

SAYAD, Abdelmalek. Uma pobreza 'exótica': a imigração argelina na França. Revista Brasileira de Ciências Sociais, nº17, pp.4-107, 1991.

TORPEY, John. A Invenção do Passaporte - Vigilância, Cidadania e o Estado. Lisboa: Temas e Debates, 2003.

Recebido: 18/09/2012

Aprovado: 10/12/2012 